\title{
Ginseng Berry and its Biological Effects as a Natural Phytochemical
}

Juewon Kim ${ }^{1,2 \dagger}$, Si Young Cho' ${ }^{1 \dagger}$, Su Hwan Kim¹, Sunmi Kim¹, Chan-Woong Park', Donghyun Cho', Dae Bang Seo ${ }^{1 *}$ and Song Seok Shin ${ }^{1 *}$

${ }^{1} R \& D$ Unit, Amore Pacific Corporation, Yongin-si, Gyeonggi-do 446-729, Republic of Korea

${ }^{2}$ Department of Integrated Biosciences, University of Tokyo, Chiba 277-8562, Japan

${ }^{+}$These authors contributed equally to this work

\begin{abstract}
A recent trial in the development of new medications and immune-modulatory agents is to search for candidates among natural products because they have relatively low toxicities in clinical applications. Ginseng has been used as a traditional medicine in Asia and has demonstrated efficacy against various human diseases, such as viral infectious diseases, diabetes, atherosclerosis, and cancer. Recent studies and clinical cases have enhanced the interest in the potential biological effects of the ginseng berry, an association that appears to be due to the phytochemical content of this fruit. The ginseng berry has various bioactivities, such as anti-diabetic, anti-oxidation, anti-neuro degeneration, anti-inflammation, anti-cancer, and enhancement of sexual function bioactivities. Moreover, syringaresinol, the effective anti-aging component of the ginseng berry, has the ability to stimulate longevity via gene activation. Further molecular and clinical studies are necessary to uncover the numerous bioactive substances in the ginseng berry that contribute to public health.
\end{abstract}

Keywords: Ginseng berry; Ginsenoside Re; Syringaresinol; Panax ginseng; Phytochemical

\section{Introduction}

\section{Ginseng berry bioactive content and composition}

The bioactive components of ginseng are triterpene glycosides or saponins, which are commonly regarded as ginsenosides. It has been reported that ginsenosides are the most effective agents in ginseng in the treatment and prevention of cancer and the regulation of blood glucose and blood pressure [1]. Ginsenosides are divided into three major groups based on the triterpene aglycones: panaxadiol, panaxytriol, and olenolic acid derivatives [2]. Other chemical compounds from Panax ginseng include alkanes, alkynes, sterols, fatty acids, monotriterpenes, phenylpropanoids, kairomones, carbohydrates (sugars and polysaccharides), amines, flavonoids, organic acids and vitamins. In addition to amino acids, nucleic acids, various enzymes and inorganic compounds are obtained from ginseng [3]. More than 60 different types of ginsenoside have been identified that are contained in the plant roots, leaves and fruits [4,5]. Because different parts of the plant contain distinct ginsenoside content, the pharmacological activity of the various parts of the plant may be different. Recent studies have demonstrated that the ginseng berry has a different ginsenoside profile and higher ginsenoside content than the root [6]. Interestingly, among the ginsenosides, ginseng berry extract contains high levels of ginsenoside Re, amounting to almost more than 30-40 times that of ginseng root, indicating that the ginseng berry may be a superior form to ginseng root extract for ingesting a large amount of ginsenoside Re [7]. In addition, ginseng berry extract contains larger amounts of vitamin $\mathrm{E}$, vitamin $\mathrm{K}$, folic acid, and potassium than the raw materials (i.e., skin, flesh, juice) of ginseng. Currently, ginseng berry extract is being evaluated in clinical and preclinical trials because its components are more efficacious as compared to ginseng root extract.

\section{Ginseng berry: preventive and therapeutic roles}

Because the ginseng berry has more abundant ginsenoside content than the root parts [8], the ginseng berry not only exhibits ginseng root-like effects but also has many other specific biological activities. Moreover, in addition to ginsenoside Re, the ginseng berry contains other bioactive components that can be efficiently absorbed from dietary ginseng berry extract [7]. Here, we review the pharmacological activities of a whole extract of the ginseng berry as well as evidence suggesting the potential of a novel anti-aging compound.
Anti-diabetic activity: A previous study reported that ginseng berry extract exhibited greater hypoglycemic activity as compared to the same dosage of a root extract [9], and the consumption of ginseng berry extract increased insulin secretion and ameliorated hyperglycemia in diabetic mice $[10,11]$. The anti-diabetic effects of the ginseng berry that have been discussed focus on effective components [12], reduced blood glucose levels [13-16], and administration [17,18]. A recent study revealed that ginseng berry extract improved insulin sensitivity in aged mice by increasing protein levels of tyrosine phosphorylated insulin receptor substrate-1 and insulin resistance-related protein AKT [19].

Anti-cancer activity: Recent studies have reported that the ginseng berry exhibits anti-cancer activity in in vitro [20-25] and in vivo $[26,27]$, as well as the ability to attenuate chemotherapy-induced side effects $[28,29]$; these effects result from the promotion of dendritic cell maturation. Interestingly, the ginseng berry induced a higher degree of co-stimulatory molecule up regulation than the root extract at the same concentrations [30]. These studies indicate that the ginseng berry is an intense tumor therapeutic vaccine adjuvant that can be used in investigations and clinical research.

Anti-inflammation and anti-oxidative activity: The ginseng berry has been shown to suppress reactive oxygen species production $[31,32], N F-\kappa B$ activation [6], and inflammatory gene expression [33] in vitro and in vivo. The ginseng berry suppressed atherosclerotic lesion development by inhibiting NF- $\kappa \mathrm{B}$-mediated atherogenic inflammatory gene expression through the induction of antioxidant enzymes without lowering serum lipid levels in a hyper lipidemic mouse model [6]. Moreover, chronic pretreatment with ginseng berry attenuated

*Corresponding authors: Dae Bang Seo, Beauty Food Research Institute, R\&D Unit, Amore Pacific Corporation, Yongin-si, Gyeonggi-do 446-729, Republic of Korea, Tel: +82312805975; E-mail: sdbang@amorepacific.com

Song Seok Shin, Beauty Food Research Institute, R\&D Center, Amore Pacific Corporation, Yongin-si, Gyeonggi-do 446-729, Republic of Korea, Tel: +82312805601; E-mail: ssshin@amorepacific.com

Received February 25, 2016; Accepted March 01, 2016; Published March 08, 2016

Citation: Kim J, Cho SY, Kim SH, Kim S, Park CW, et al. (2016) Ginseng Berry and its Biological Effects as a Natural Phytochemical. Nat Prod Chem Res 4: 209. doi:10.4172/2329-6836.1000209

Copyright: (c) $2016 \mathrm{Kim} \mathrm{J}$, et al. This is an open-access article distributed under the terms of the Creative Commons Attribution License, which permits unrestricted use, distribution, and reproduction in any medium, provided the original author and source are credited. 
oxidative stress in cardiomyocytes [34] and up regulated human umbilical vein endothelial cell proliferation and migration [35].

Anti-sexual dysfunction: Sexual dysfunction has a severe impact on the quality of life of affected individuals. Previous studies reported that more than half of the male population has some degree of erectile dysfunction [36], and one-third of the global male population, across all ages, has some degree of premature ejaculation [37]. To treat these symptoms, PDE5 inhibitors and selective serotonin reuptake inhibitors are used; however, these drugs can produce negative side effects, including headache, gastrointestinal disorder, muscle pain, and blurred vision and may have dangerous interactions with other medications $[38,39]$. To avoid the risks of side effects, people often turn to dietary ingredients, such as ginseng. Ginsenosides have been shown to enhance nitric oxide production by inducing nitric oxide synthase activity [40,41]. Recently, ginsenoside $\operatorname{Rg} 1$, which is abundantly present in the ginseng berry, was also shown to improve male copulation behavior via the nitric oxide/CGMP pathway [42]. Clinical observation of patients after 8-week oral treatment indicated that ginseng berry improved all domains of sexual function including erectile dysfunction and premature ejaculation [43]. The ginseng berry had a greater relaxation effect on rabbit corpus cavernosum smooth muscle than did ginseng root extract and increased intracavernosal pressure in a rat model in both a dose- and duration-dependent manner. This relaxing effect might be mediated by nitric oxide production [44].

Anti-neurodegeneration activity: There has been a growing interest in a number of pharmacological approaches to help slow the rate of both cognitive and functional declines associated with aging. Continued research indicates the occurrence of neuronal and behavioral deficits during aging, even in the absence of neurodegenerative diseases such as Alzheimer's diseases and Parkinson's diseases. Recently, several dietary supplements with either strawberry or blueberry extracts have been reported to reduce some neurological deficits in animal models of aging $[45,46]$. Fruits are beneficial in both forestalling and reversing the deleterious effects of aging on neuronal communication and behavior [47]. The neuroactive effects of free amino acids in ginseng seed and berries have been proposed [48]. It has been suggested that one potential mechanism by which the ginseng berry improves various neurological functions is via an interaction with the cholinergic and serotoninergic neurotransmitter systems. The suggestion of this pathway is supported by reports that have shown that selective damage to serotonergic neurons affects certain aspects of memory functions, specifically, spatial working memory [49,50]. Moreover, one of the behavioral paradigms found to be improved by ginseng berry supplementation was that of electroconvulsive shock, which is known to modulate the cholinergic neurotransmitter system, especially within brain areas, such as the hippocampus [51-53]. It has also been proposed that the ginseng berry enhance the components of cholinergic systems, such as choline acetyltransferase, which is also thought to be important in the formation of memory [54-56]. Although there have been a number of studies emphasizing the potential helpful effects of ginseng berry on cognitive performance in animal models, few epidemiological reports have been performed. In fact, a comprehensive investigation of the literature found few studies exploring the effects of ginseng berry on human cognitive performance, in which significant improvement in mental arithmetic and abstraction tests were reported [57-59].

\section{Exploring Other Bioactive Constituents in the Ginseng Berry and Syringaresinol}

Because of its numerous potent biological activities, there have been many efforts to discover other useful components in the ginseng berry besides ginsenoside. The ginseng berry has many unique bioactive constituents compared to the generally used ginseng root. Recently, a lignin compound, syringaresinol(4,4'-(1S,3aR,4S,6aR)-tetrahydro$1 \mathrm{H}, 3 \mathrm{H}$-furo[3,4-c]furan-a,4-diylbis(2,6-dimethoxyphenol)), was isolated from panax ginseng pulp and found to activate SIRT1 gene expression, leading to delayed cellular senescence and improved endothelial cell function in endothelial cells [60]. Syringaresinol treatment induced the binding of FoxO3a to the SIRT1 promoter in a sequence-specific manner, leading to the induction of SIRT1 expression. Syringaresinol exists either exclusively as one enantiomer or as enantiomeric mixtures in plant foods. Syringaresinol has Enantioselective effects upon biological activity [61] and also has protective effects against hypoxia/reoxygenation-induced injury. Syringaresinol caused the destabilization of hypoxia-inducible factor 1 following hypoxia/reoxygenation and then protected cellular damage and death in a FOXO3-dependent mechanism [62].

\section{Conclusion}

The ginseng berry is a rich source of dietary bioactivities and has various biological activities in addition to that of the ginseng root. It possesses higher ginsenoside content than its root, which has been traditionally used in herbal medicine for many human diseases and age-related attenuates. In this study, we reviewed the biological and pharmacological activities of the ginseng berry, including antidiabetic, anti-cancer, anti-inflammation, anti-neurodegeneration, and also sexual function effects. In addition, an anti-aging component of the ginseng berry, syringaresinol, has the potential for activating the longevity genes sirt1 and foxo. According to numerous reports, the ginseng berry has the potential to be widely used as an anti-aging reagent for many age-related human diseases and to increase vitality. Basic research has suggested a number of potential mechanisms of action for ginseng berry bioactive substances, although further molecular research is necessary. Furthermore, the optimal dose of ginseng berry bioactive substances has not been determined for urinary tract or cardiovascular health. Another major deficiency concerning the evaluation of existing clinical reports is the lack of quantification of ginseng berry bioactive substances or assessment of their concentration in blood or urine. There is potent experimental evidence that ginseng berry bioactive substances have favorable effects on blood glucose metabolism, blood pressure, oxidative stress, inflammation, cancer, and endothelial function. As noted, the average daily fruit consumption is substantially less than what is recommended. In part, encouraging consumption of a greater proportion of plant foods, including fruit, to achieve a healthy dietary pattern will help to attain the recommended dietary intake of micronutrients. Although reference intake values have yet to be developed for phytochemicals, there is a growing consensus that their bioactivities importantly contribute to promoting public health and reducing the risk of chronic diseases. Berry fruit, including the ginseng berry, represents an especially rich source of many phenolic acids and flavonoids that have been associated with these benefits. Additional research that clarifies specific dietary guidance with regard to the type of berry should help elevate our intake of these bioactive moieties.

\section{Acknowledgements}

All authors read and approved the final manuscript. I thank all lab members for the discussions. In addition to their contribution to the writing, D.B.S., S.S.S., and S.Y.C. outlined and co-edited this article.

\section{References}

1. Yin J, Zhang $\mathrm{H}$, Ye J (2008) Traditional Chinese medicine in treatment of metabolic syndrome. Endocr Metab Immune Disord Drug Targets 8: 99-111. 
2. Kim TH, Lee SM (2010) The effects of ginseng total saponin, panaxadiol and panaxatriol on ischemia/reperfusion injury in isolated rat heart. Food Chem Toxicol 48: 1516-1520

3. Chang YS, Seo EK, Gyllenhaal C, Block KI (2003) Panax ginseng: a role in cancer therapy? Integr Cancer Ther 2: 13-33.

4. Nakamura S, Sugimoto S, Matsuda H, Yoshikawa M (2007) Medicinal flowers. XVII. New dammarane-type triterpene glycosides from flower buds of American ginseng, Panax quinquefolium L. Chem Pharm Bull (Tokyo) 55: 1342-1348.

5. Qu C, Bai Y, Jin X, Wang Y, Zhang K, et al. (2009) Study on ginsenosides in different parts and ages of Panax quinquefolius. Food Chemi 115: 340-346.

6. Kim CK, Cho DH, Lee KS, Lee DK, Park CW, et al. (2012) Ginseng Berry Extract Prevents Atherogenesis via Anti-Inflammatory Action by Upregulating Phase II Gene Expression. Evid Based Complement Alternat Med 2012: 490301.

7. Joo KM, Lee JH, Jeon HY, Park CW, Hong DK, et al. (2010) Pharmacokinetic study of ginsenoside $\mathrm{Re}$ with pure ginsenoside $\mathrm{Re}$ and ginseng berry extracts in mouse using ultra performance liquid chromatography/mass spectrometric method. J Pharm Biomed Anal 51: 278-283.

8. Zhao YQ, Yuan CL (1993) Chemical constituents of the fruit of Panax ginseng C. A. Meyer. Zhongguo Zhong Yao Za Zhi 18: 296-297, 319.

9. Dey L, Xie JT, Wang A, Wu J, Maleckar SA, et al. (2003) Anti-hyperglycemic effects of ginseng: comparison between root and berry. Phytomedicine 10 600-605.

10. Park EY, Kim HJ, Kim YK, Park SU, Choi JE, et al. (2012) Increase in Insulin Secretion Induced by Panax ginseng Berry Extracts Contributes to the Amelioration of Hyperglycemia in Streptozotocininduced Diabetic Mice. J Ginseng Res 36: 153-160.

11. Xie JT, Wu JA, Mehendale S, Aung HH, Yuan CS (2004) Anti-hyperglycemic effect of the polysaccharides fraction from American ginseng berry extract in ob/ob mice. Phytomedicine 11: 182-187.

12. Attele AS, Zhou YP, Xie JT, Wu JA, Zhang L, et al. (2002) Antidiabetic effects of Panax ginseng berry extract and the identification of an effective component. Diabetes 51: 1851-1858.

13. Xie JT, Zhou YP, Dey L, Attele AS, Wu JA, et al. (2002) Ginseng berry reduces blood glucose and body weight in $\mathrm{db} / \mathrm{db}$ mice. Phytomedicine 9: 254-258.

14. Xie JT, Aung HH, Wu JA, Attel AS, Yuan CS (2002) Effects of American ginseng berry extract on blood glucose levels in ob/ob mice. Am J Chin Med 30: 187-194

15. Xie JT, Wang CZ, Ni M, Wu JA, Mehendale SR, et al. (2007) American ginseng berry juice intake reduces blood glucose and body weight in ob/ob mice. J Food Sci 72: S590-594.

16. Kim ST, Kim HB, Lee KH, Choi YR, Kim HJ, et al. (2012) Steam-dried ginseng berry fermented with Lactobacillus plantarum controls the increase of blood glucose and body weight in type 2 obese diabetic $\mathrm{db} / \mathrm{db}$ mice. J Agric Food Chem 60: 5438-5445.

17. Dey L, Zhang L, Yuan CS (2002) Anti-diabetic and anti-obese effects of ginseng berry extract: comparison between intraperitoneal and oral administrations. Am J Chin Med 30: 645-647.

18. Yuan CS, Tanaka $\mathrm{H}$ (2011) Bioactivity of American ginseng by knockout extract preparation using monoclonal antibody. Curr Drug Discov Technol 8: 32-41.

19. Seo E, Kim S, Lee SJ, Oh BC, et al. (2015) Ginseng berry extract supplementation improves age-related decline of insulin signaling in mice. Nutrients 7: 3038-3053.

20. Xie JT, Wang CZ, Zhang B, Mehendale SR, Li XL, et al. (2009) In vitro and in vivo anticancer effects of American ginseng berry: exploring representative compounds. Biol Pharm Bull 32: 1552-1558

21. Wang W, Zhao Y, Rayburn ER, Hill DL, Wang H, et al. (2007) In vitro anticancer activity and structure-activity relationships of natural products isolated from fruits of Panax ginseng. Cancer Chemother Pharmacol 59: 589-601.

22. Wang CZ, Xie JT, Fishbein A, Aung HH, He H, et al. (2009) Antiproliferative effects of different plant parts of Panax notoginseng on SW480 human colorectal cancer cells. Phytother Res 23: 6-13.

23. Li XL, Wang CZ, Sun S, Mehendale SR, Du W, et al. (2009) American ginseng berry enhances chemopreventive effect of 5-FU on human colorectal cance cells. Oncol Rep 22: 943-952.
24. Xie JT, Du GJ, McEntee E, Aung HH, He H, et al. (2011) Effects of Triterpenoid Glycosides from Fresh Ginseng Berry on SW480 Human Colorectal Cancer Cell Line. Cancer Res Treat 43: 49-55.

25. Jang HJ, Han IH, Kim YJ, Yamabe N, Lee D, et al. (2014) Anticarcinogenic effects of products of heat-processed ginsenoside Re, a major constituent of ginseng berry, on human gastric cancer cells. J Agric Food Chem 62: 2830 2836 .

26. Hao M, Wang W, Zhao Y, Zhang R, Wang H (2011) Pharmacokinetics and tissue distribution of 25-hydroxyprotopanaxadiol, an anti-cancer compound isolated from Panax ginseng, in athymic mice bearing xenografts of human pancreatic tumors. Eur J Drug Metab Pharmacokinet 35: 109-113.

27. Lee S, Kim MG, Ko SK, Kim HK, Leem KH, et al. (2014) Protective effect of ginsenoside $\mathrm{Re}$ on acute gastric mucosal lesion induced by compound 48/80. J Ginseng Res 38: 89-96.

28. Mehendale SR, Aung HH, Yin JJ, Lin E, Fishbein A, et al. (2004) Effects of antioxidant herbs on chemotherapy-induced nausea and vomiting in a rat-pica model. Am J Chin Med 32: 897-905.

29. Mehendale S, Aung H, Wang A, Yin JJ, Wang CZ, et al. (2005) American ginseng berry extract and ginsenoside Re attenuate cisplatin-induced kaolin intake in rats. Cancer Chemother Pharmacol 56: 63-69.

30. Zhang W, Cho SY, Xiang G, Min KJ, Yu Q, et al. (2015) Ginseng Berry Extract Promotes Maturation of Mouse Dendritic Cells. PLoS One 10: e0130926.

31. Shao ZH, Xie JT, Vanden Hoek TL, Mehendale S, Aung H, et al. (2004) Antioxidant effects of American ginseng berry extract in cardiomyocytes exposed to acute oxidant stress. Biochim Biophys Acta 1670: 165-171.

32. Xie JT, Shao ZH, Vanden Hoek TL, Chang WT, Li J, et al. (2006) Antioxidant effects of ginsenoside Re in cardiomyocytes. Eur J Pharmacol 532: 201-207.

33. Bae HM, Cho OS, Kim SJ, Im BO, Cho SH, et al. (2012) Inhibitory effects of ginsenoside re isolated from ginseng berry on histamine and cytokine release in human mast cells and human alveolar epithelial cells. J Ginseng Res 36 : 369-374.

34. Mehendale SR, Wang CZ, Shao ZH, Li CQ, Xie JT, et al. (2006) Chronic pretreatment with American ginseng berry and its polyphenolic constituents attenuate oxidant stress in cardiomyocytes. Eur J Pharmacol 553: 209-214.

35. Lei Y, Gao Q, Chen KJ (2008) Effects of extracts from Panax notoginseng and Panax ginseng fruit on vascular endothelial cell proliferation and migration in vitro. Chin J Integr Med 14: 37-41.

36. Feldman HA, Goldstein I, Hatzichristou DG, Krane RJ, McKinlay JB (1994) Impotence and its medical and psychosocial correlates: results of the Massachusetts Male Aging Study. J Urol 151: 54-61.

37. Laumann EO, Nicolosi A, Glasser DB, Paik A, Gingell C, et al. (2005) Sexua problems among women and men aged $40-80 \mathrm{y}$ : prevalence and correlates identified in the Global Study of Sexual Attitudes and Behaviors. Int J Impot Res 17: 39-57.

38. Moreira SG Jr, Brannigan RE, Spitz A, Orejuela FJ, Lipshultz LI, et al. (2000) Side-effect profile of sildenafil citrate (Viagra) in clinical practice. Urology 56 474-476.

39. Ferguson JM (2001) SSRI Antidepressant Medications: Adverse Effects and Tolerability. Prim Care Companion J Clin Psychiatry 3: 22-27.

40. Li Z, Niwa Y, Sakamoto S, Shono M, Chen X, et al. (2000) Induction of inducible nitric oxide synthase by ginsenosides in cultured porcine endothelial cells. Life Sci 67: 2983-2989.

41. Kim ND, Kim EM, Kang KW, Cho MK, Choi SY, et al. (2003) Ginsenoside R3 inhibits phenylephrine-induced vascular contraction through induction of nitric oxide synthase. Br J Pharmacol 140: 661-670.

42. Wang X, Chu S, Qian T, Chen J, Zhang J (2010) Ginsenoside Rg1 improves male copulatory behavior via nitric oxide/cyclic guanosine monophosphate pathway. J Sex Med 7: 743-750.

43. Choi YD, Park CW, Jang J, Kim SH, Jeon HY, et al. (2013) Effects of Korean ginseng berry extract on sexual function in men with erectile dysfunction: a multicenter, placebo-controlled, double-blind clinical study. Int J Impot Res 25 $45-50$

44. Cho KS, Park CW, Kim CK, Jeon HY, Kim WG, et al. (2013) Effects of Korean ginseng berry extract (GB0710) on penile erection: evidence from in vitro and in vivo studies. Asian J Androl 15: 503-507. 
45. Gemma C, Mesches MH, Sepesi B, Choo K, Holmes DB, et al. (2002) Diets enriched in foods with high antioxidant activity reverse age-induced decreases in cerebellar beta-adrenergic function and increases in proinflammatory cytokines. J Neurosci 22: 6114-6120.

46. Wang Y, Chang CF, Chou J, Chen HL, Deng X, et al. (2005) Dietary supplementation with blueberries, spinach, or spirulina reduces ischemic brain damage. Exp Neurol 193: 75-84.

47. Joseph JA, Shukitt-Hale B, Casadesus G (2005) Reversing the deleterious effects of aging on neuronal communication and behavior: beneficial properties of fruit polyphenolic compounds. Am J Clin Nutr 81: 313-316.

48. Kuo YH, Ikegami F, Lambein $F$ (2003) Neuroactive and other free amino acids in seed and young plants of Panax ginseng. Phytochemistry 62: 1087-1091.

49. Lehmann O, Jeltsch H, Lehnardt O, Pain L, Lazarus C, et al. (2000) Combined lesions of cholinergic and serotonergic neurons in the rat brain using 192 IgG-saporin and 5,7-dihydroxytryptamine: neurochemical and behavioural characterization. Eur J Neurosci 12: 67-79.

50. Balse E, Lazarus C, Kelche C, Jeltsch H, Jackisch R, et al. (1999) Intrahippocampal grafts containing cholinergic and serotonergic fetal neurons ameliorate spatial reference but not working memory in rats with fimbria-fornix cingular bundle lesions. Brain Res Bull 49: 263-272.

51. Mingo NS, Cottrell GA, Mendonça A, Gombos Z, Eubanks JH, et al. (1998) Amygdala-kindled and electroconvulsive seizures alter hippocampal expression of the $\mathrm{m} 1$ and $\mathrm{m} 3$ muscarinic cholinergic receptor genes. Brain Res 810: 9-15.

52. Vann SD, Brawn MW, Erichsen JT, Aggleton JP (2000) Fos imaging reveals differential patterns of hippocampal and para-hippocampal subfield activation in rats in response to different spatial memory tests. J Neurosci 20: 2711-2718.

53. Zhao W, Chen H, Xu H, Moore E, Meiri N, et al. (1999) Brain insulin receptors and spatial memory. Correlated changes in gene expression, tyrosine phosphorylation, and signaling molecules in the hippocampus of water maze trained rats. J Biol Chem 274: 34893-34902.
54. Stancampiano R, Cocco S, Cugusi C, Sarais L, Fadda F (1999) Serotonin and acetylcholine release response in the rat hippocampus during a spatial memory task. Neuroscience 89: 1135-1143.

55. Darnaudéry M, Koehl M, Piazza PV, Le Moal M, Mayo W (2000) Pregnenolone sulfate increases hippocampal acetylcholine release and spatial recognition. Brain Res 852: 173-179.

56. Meck WH, Williams CL (1999) Choline supplementation during prenata development reduces proactive interference in spatial memory. Brain Res Dev Brain Res 118: 51-59.

57. D'Angelo L, Grimaldi R, Caravagi M, Marcoli M, Perucca E, et al. (1986) A double-blind placebo-controlled clinical study on the effect of a standardized ginseng extract on psychomotor performance in healthy volunteers. J Ethnopharmacol 16: 15-22.

58. Sorensen H, Sonne J (1996) A double-masked study of the effect of ginseng on cognitive functions. Curr Ther Res 57: 959-968.

59. Winther K, Ranlov C, Rein E, Mehlsen J (1997) Russian root improves cognitive functions in middle-aged people whereas Ginkgo biloba seems effective only in the elderly. J Neurol Sci 150: S90.

60. Cho SY, Cho M, Seo DB, Lee SJ, Suh Y (2013) Identification of a smal molecule activator of SIRT1 gene expression. Aging (Albany NY) 5: 174-182.

61. Park HW, Cho SY, Kim HH, Yun BS, Kim JU, et al. (2015) Enantioselective induction of SIRT1 gene by syringaresinol from Panax ginseng berry and Acanthopanax senticosus Harms stem. Bioorg Med Chem Lett 25: 307-309.

62. Cho SY, Cho M, Kim J, Kaeberlein M, Lee SJ, et al. (2014) Syringaresino protects against hypoxia/reoxygenation-induced cardiomyocytes injury and death by destabilization of HIF-1a in a FOXO3-dependent mechanism. Oncotarget 6: 43-55. 